\title{
On the Method of Occlusion and Application of Occluder for Treatment of Children Ophthalmic Diseases
}

\author{
Alfred L Tsykalo*1 and Antuanetta S Senyakina ${ }^{2}$ \\ ${ }^{1}$ Doctor of Sciences, Head of Association of the Ecological and Social Safety, Odessa, Ukraine \\ ${ }^{2}$ Doctor of Sciences, Ryvne State Medical University, Ryvne, Ukraine
}

Corresponding author: Alfred L Tsykalo, Doctor of Sciences, Head of Association of the Ecological and Social Safety, Odessa, Ukraine

\begin{tabular}{|c|c|}
\hline ARTICLE INFO & ABSTRACT \\
\hline Received: 幽 October 21, 2020 & Citation: Alfred L Tsykalo, Antuanetta S Senyakina. On the Method of Occlusion and \\
\hline Published: 慧October 30, 2020 & $\begin{array}{l}\text { Application of Occluder for Treatment of Children Ophthalmic Diseases. Biomed J Sci \& } \\
\text { Tech Res 31(4)-2020. BJSTR. MS.ID.005122. }\end{array}$ \\
\hline
\end{tabular}

\section{Opinion}

The main reason for decreased vision in $25-30 \%$ of children is hereditary, congenital or acquired in an early reward (up to three years) diseases of the refractive media of the eye, pathology of the notorious and oculomotor muscles, manifested in anomalies in the shape, size and refractive power of the cornea, lens of the eye and their transparency, which leads to anomalies of eye refraction (myopia, hyperopia, astigmatism), various types of strabismus and accommodation disorders. These diseases exclude the possibility of forming a correct, clear visual image, because of which the main visual function, visual acuity, decreases. The eye diseases listed above can be unilateral (in one eye), or bilateral-in both eyes (binocular). However, the latter, as a rule, are more pronounced in one eye of a child than in the other (paired), as a result of which the vision of this worse eye is lower than that of the other. From an early age, the child constantly gets used to using the best eye for vision, which leads to functional underdevelopment, to a halt in the development of vision of the paired (worse) eye, and to amblyopia. Refractive errors (myopia, hyperopia, astigmatism) lead to the development of amblyopia in $70-85 \%$ of ametropias and unilateral cross-eyed contributes to the occurrence of squinting eye amblyopia in $80-90 \%$ of patients. However, the treatment of such children is effective only at preschool age.

So, the most effective, simple, affordable treatment method that does not require visits to eye offices and hospitals (which is very important, especially for the population of developing countries with a high birth rate, low income, and an underdeveloped health care system) is the method occlusion, proposed back in 1743 by J. L. L. Buffon. As is known occlusion is a complete or partial exclusion of the best eye's vision from the act of binocular vision to ensure visual work with only one, the worst-looking eye for its monocular visual stimulation. For this purpose, various types of occlude are currently used, attached to the frame of spectacles in the form of opaque and translucent paper or plastic films, as well as optical glass lenses (spherical biconvex or contact lenses). In recent years, spectacles based on the use of liquid crystal films have also been offered. However, the types of occlude listed above have several significant functional and economic disadvantages. The main ones are: complete exclusion of one eye from the act of binocular vision; the inability to quantitatively dose and change the degree of decrease in visual acuity in the best eye during the application of the occlude; the need for an energy source; the need for frequent replacement of device elements, as well as the high cost of the occlude.

In connection with the above, the development of an occlude that would satisfy the following requirements of ophthalmological practice remains relevant:

a. Occlude in the form of a simple attachment to the frame of glasses, correcting the patient's ametropia.

b. Occlude, providing the ability to quantitatively change the magnitude of the reduction in vision of the best (leading) eye. 
c. Maximum possible simplicity of the occlude design.

d. Ease and low cost of repair work.

e. No need to replace the occlude during treatment.

f. No need for an energy source, and, accordingly, no need to recharge or replace the batteries used, etc.

ISSN: 2574-1241

DOI: 10.26717/BJSTR.2020.31.005122

Alfred L Tsykalo. Biomed J Sci \& Tech Res

(C) This work is licensed under Creative

Submission Link: https://biomedres.us/submit-manuscript.php g. Minimal weight, optimal appearance, comfort in use (especially when the device is used by children).

h. Low cost of occlude, available for all segments of the population (including the population of developing countries and population of countries with low incomes).

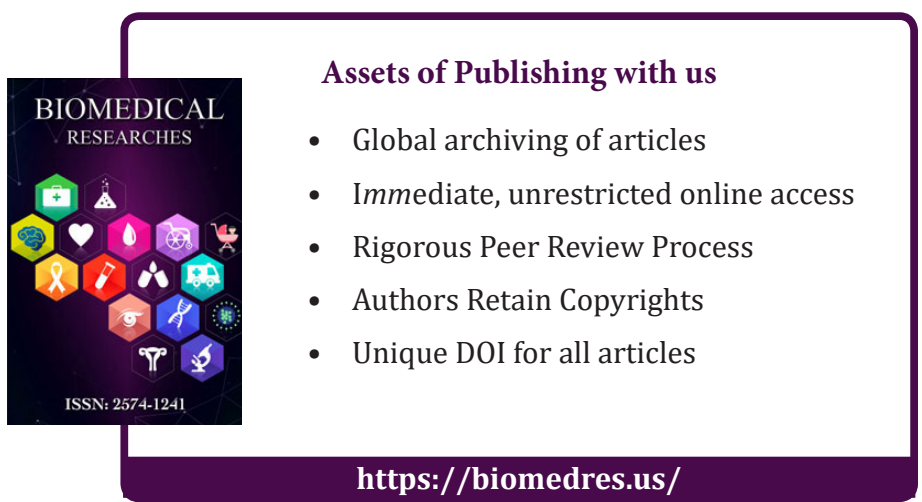

